\title{
Loss of Clusterin Limits Atherosclerosis in Apolipoprotein E-deficient Mice via Reduced Expression of Egr-1 and TNF- $a$
}

\author{
Narisato Hamada ${ }^{1}$, Masaaki Miyata ${ }^{1}$, Hideyuki Eto ${ }^{1}$, Yoshiyuki Ikeda ${ }^{1}$, Takahiro Shirasawa ${ }^{1}$, Yuichi Akasaki ${ }^{1}$, \\ Takahiro Miyauchi ${ }^{1}$, Yuko Furusho ${ }^{1}$, Aya Nagaki ${ }^{1}$, Bruce Jefferson Aronow ${ }^{2}$, and Chuwa Tei ${ }^{1}$

\footnotetext{
${ }^{1}$ Department of Cardiovascular, Respiratory and Metabolic Medicine, Graduate School of Medicine, Kagoshima University, Kagoshima, Japan

${ }^{2}$ Cincinnati Children's Hospital Medical Center, Cincinnati, OH, USA
}

\begin{abstract}
Aim: Whether clusterin/apolipoprotein $\mathrm{J}$ is antiatherogenic or proatherogenic is controversial. We reported that clusterin was markedly induced in media and neointima after vascular injury and that reduced clusterin expression reduced the proliferation of vascular smooth muscle cells (VSMCs), which induced G1 arrest via $\mathrm{p} 53$ and $\mathrm{p} 21$. The purpose of this study was to investigate the physiological function of clusterin in atherosclerosis using double-knockout mice (D-KO) of apolipoprotein E-deficient mice (apoE-KO) and clusterin-deficient mice (CLU-KO).

Methods and Results: Atherosclerotic lesions in the aortic root were quantitated at 20 weeks of age. Atherosclerotic lesions of D-KO were significantly smaller than those of apoE-KO (D-KO: $0.176 \pm$ $0.078 \mathrm{~mm}^{2}$ vs. apoE-KO: $\left.0.365 \pm 0.164 \mathrm{~mm}^{2}, p<0.001\right)$. To identify underlying atherosclerotic mechanisms that were blocked by loss of clusterin, we performed immunohistochemical analysis of Egr-1. Egr-1 immunoreactivity in the nuclei of VSMCs in atherosclerotic lesions of apoE-KO was upregulated, whereas it was not in $\mathrm{D}-\mathrm{KO}$ lesions. Western blotting demonstrated that the expression levels of Egr-1 and TNF- $\alpha$ in the D-KO were significantly lower than those in the apoE-KO. When VSMCs and macrophages were obtained from D-KO and apoE-KO, Western blotting showed that the expression levels of Egr-1 and TNF- $\alpha$ in VSMCs and macrophages of D-KO were significantly lower than those of apoE-KO.

Conclusion: Loss of clusterin strongly suppressed apoE-KO-induced atherosclerotic lesions at a step prior to the expression of Egr-1 and TNF- $\alpha$, suggesting that clusterin is a candidate for an antiatherogenic target.
\end{abstract}

J Atheroscler Thromb, 2011; 18:209-216.

Key words; Clusterin, Atherosclerosis, Egr-1, TNF- $\alpha$

\section{Introduction}

Atherosclerosis is a progressive disease characterized by the accumulation of lipids and fibrous elements in the large arteries and constitutes the single most important contributor to the growing burden of cardiovascular disease ${ }^{1)}$. Atherosclerosis is an inflam-

Address for correspondence: Masaaki Miyata, Department of Cardiovascular, Respiratory and Metabolic Medicine, Graduate School of Medicine, Kagoshima University, 8-35-1

Sakuragaoka, Kagoshima 890-8520, Japan

E-mail: miyatam@m3.kufm.kagoshima-u.ac.jp

Received: May 7, 2010

Accepted for publication: October 6, 2010 matory disease ${ }^{2)}$. Oxidized low-density lipoprotein is believed to play a key role in cellular dysfunction, as well as cholesterol accumulation and subsequent foam-cell transformation in macrophages and phenotypically modulated vascular smooth muscle cells (VSMCs) ${ }^{3,4)}$; however, the precise mechanisms that evoke inflammatory processes in plaque formation and progression remain incompletely defined.

Clusterin (also designated apolipoprotein J) is an extracellular, highly conserved, and heavily glycosylated disulfide-linked heterodimer with an apparent molecular mass of $70 \mathrm{kDa}^{5}$. Clusterin is constitutively expressed in almost all mammalian tissues by different cell types, including epithelial and specific neuronal 
cells. Furthermore, clusterin is found in all body fluids, including plasma, seminal plasma, milk, urine, and cerebrospinal fluid ${ }^{5,6}$. The wide distribution and sequence conservation of clusterin suggest that this protein performs functions of fundamental biological importance. It is involved in numerous physiological processes important for carcinogenesis and tumor growth, including apoptotic cell death, cell cycle regulation, DNA repair, cell adhesion, tissue remodeling, lipid transportation, membrane recycling, and immune system regulation ${ }^{7}$. Furthermore, the expression of clusterin is upregulated in acute myocardial infarction, atherosclerosis ${ }^{8)}$, myocarditis ${ }^{9)}$, Alzheimer's disease ${ }^{10)}$, several cancers ${ }^{11)}$, oxidative stress, heat shock ${ }^{12)}$, and after injury in general ${ }^{6}$.

We reported that clusterin was markedly induced in media and neointima after vascular injury and that the expression of clusterin stimulated the proliferation and migration of cultured VSMCs in vitro ${ }^{13)}$. In addition, Millis et al. reported that clusterin regulates VSMC nodule formation and migration ${ }^{14)}$. Moreover, clusterin antisense was reported to inhibit the proliferation of cultured VSMCs obtained from neointima after ballooning in vitro ${ }^{15}$. Recently, we reported that reduced clusterin expression reduced the proliferation of VSMCs and induced G1 arrest via p53 and p21 ${ }^{16)}$. Although clusterin is expressed in atherosclerosis lesions, it is not clear whether it is antiatherogenic or proatherogenic.

The purpose of this study was to investigate the physiological function of clusterin in atherosclerosis using double-knockout mice (D-KO) of apolipoprotein E-deficient mice (apoE-KO) and clusterin-deficient mice (CLU-KO).

\section{Materials and Methods}

\section{Generation of $\mathrm{CLU}^{-/-} / \mathrm{apoE}^{-/-}$Double-Knockout Mice (D-KO)}

We used apoE-KO mice with a C57BL/6 background that were donated by Dr. Jan L. Bresslow (Rockefeller University) and CLU-KO mice with a C57BL/6 background. CLU-KO mice were as described by McLaughlin et al. ${ }^{17)}$. Unperturbed CLU-KO mice showed a minimal phenotype, including atherosclerosis and inflammation. ApoE-KO mice were crossed with CLU-KO mice and heterozygous knockout mice were crossed until homozygous double-knockout (D-KO) mice were obtained. Genotypes for apoE and clusterin were determined by polymerase chain reaction (PCR) amplification of DNA isolated from the tail. Mice were fed a standard diet and water was available ad libitum. All animal procedures were carried out with the approval of the Animal Research Committee in accordance with the guidelines on animal experiments of the Faculty of Medicine, Kagoshima University. The study conformed to the Guide for the Care and Use of Laboratory Animals published by the United States National Institutes of Health (NIH Publication No. 85-23, revised 1996).

\section{Genotyping by Polymerase Chain Reaction}

Clusterin genotyping was performed by PCR analysis using three primers obtained from SigmaAldrich Japan (Tokyo, Japan) that amplified both wild-type and mutant alleles in the same reaction. These were: SHF-3 (5'-ACGATGTGGAAGGATGTGGAAGATGAACATG-3') forward primer, recognizing both mutant and wild-type alleles and corresponding to genomic sequences near the 5' end of the short homology fragment; apoJKO-R2 (5'-TGGTGATGGGGCTCTAGTCACCTCCCACTTC-3'), reverse wild-type primer complementary to sequences just 3' to the deleted first exon; and PGK-2 (5'-CTGCTAAAGCGCATGCTCCAGACTGCCTTG-3'), reverse knockout primer corresponding to sequences in the promoter region of the hypoxanthine phosphoribosyl transferase (HPRT) cassette. PCR for wild-type (500 $\mathrm{bp})$ and mutant $(540 \mathrm{bp}$ ) alleles was performed with cycles consisting of 3 minutes at $94^{\circ} \mathrm{C}, 45$ seconds at $52^{\circ} \mathrm{C}$, and 45 seconds at $72^{\circ} \mathrm{C}{ }^{17}$.

Apolipoprotein E genotyping used the following primers (Sigma-Aldrich Japan): antisense, 5'-GCCTA GCCGAGGGAGAGCCG-3' and sense, 5'-GCCGCCCCGACTGCATCT-3'. Resultant wild-type and deficient allele bands were 155 bp and 245 bp, respectively. PCR was performed with 35 cycles consisting of 3 minutes at $94^{\circ} \mathrm{C}, 40$ seconds at $68^{\circ} \mathrm{C}$, and $2 \mathrm{~min}-$ utes at $72^{\circ} \mathrm{C}$.

\section{Tissue Preparation and Lesion Assessment}

Male double-homozygous $\left(\mathrm{CLU}^{-1-} / \mathrm{apoE}^{-/-} ; \mathrm{D}-\mathrm{KO}\right)$ mice and male apoE knockout $\left(\mathrm{CLU}^{+/+} / \mathrm{apoE}^{-/-}\right.$; apoE-KO) mice were compared in this study. At the age of 20 weeks, mice were anesthetized with pentobarbital ( $80 \mu \mathrm{g} / \mathrm{kg}$ body weight, intraperitoneally) and fasting blood was drawn from the left ventricle of the anesthetized mice. Plasma total cholesterol, triglyceride, and HDL cholesterol levels were measured with an enzymatic kit (Kainos, Tokyo, Japan).

After blood drawing, mice were perfused with phosphate-buffered saline ( $\mathrm{pH}$ 7.4) followed by $10 \%$ neutral-buffered formalin through a catheter placed in the left ventricle. The heart with the aortic root was fixed in $10 \%$ neutral-buffered formalin, embedded in OCT, and frozen at $-80^{\circ} \mathrm{C}$. Frozen sections were cut 
into $10-\mu \mathrm{m}$ sections and fixed to glass slides. The slides were stained with oil red $\mathrm{O}$. All sections were examined under a microscope; the lipid staining of the aortic root in the histological sections was quantitated $^{18)}$.

\section{Immunohistochemical Analysis}

The heart with the aortic root was also paraffinembedded and stored at room temperature. Immunohistochemical staining was carried out on paraffinembedded sections as described previously ${ }^{19}$. After deparaffinization and hydration of specimens, the endogenous peroxidase activity was blocked and the specimens were fixed by immersion in $0.3 \% \mathrm{H}_{2} \mathrm{O}_{2}$ in methanol for 20 minutes. Immunohistochemical staining was performed with a rabbit polyclonal antibody against human Egr-1 (Santa Cruz Biotechnology, Santa Cruz, CA) using the labeled streptavidin biotin complex method (Simple-stain MAX-PO kit, Nichirei, Tokyo, Japan). After blocking with $10 \%$ rabbit or goat serum, slides were incubated overnight with a primary antibody at $4{ }^{\circ} \mathrm{C}$ in a moisture chamber. Slides were washed with Tris-buffered saline and incubated with a biotinylated secondary antibody at room temperature for 30 minutes. After washing with Tris-buffered saline, slides were incubated with streptavidin at room temperature for 30 minutes and visualized with 3,3'-diaminobenzidine.

\section{Western Blot Analysis}

Protein was extracted from the aorta of apoE-KO or $\mathrm{D}-\mathrm{KO}$ mice using the Protein and RNA Isolation System (Ambion Inc., Austin, TX). Insoluble matter was removed by centrifugation and the protein concentration was measured by a bicinchoninic acid assay (PIERCE Biotechnology Inc., Rockford, IL). Western blotting was performed with the NuPAGE ${ }^{\mathrm{TM}}$ Electrophoresis System (Invitrogen, Carlsbad, CA) as reported previously ${ }^{20)}$. Briefly, $10-\mu \mathrm{g}$ protein samples were resuspended in reduced sample buffer and then electrophoresed on a $4-12 \%$ Bis-Tris gel (Invitrogen, Carlsbad, CA) with 3-(N-morpholino) propanesulfonic acid (MOPS) running buffer and blotted on to a nitrocellulose membrane. The protein sample was then sequentially probed with a rabbit polyclonal antibody against human clusterin, ERK1, Egr-1, TNF- $\alpha$, and actin (Santa Cruz Biotechnology). Horseradish peroxidase-conjugated donkey anti-rabbit antibody (Santa Cruz Biotechnology) was then added and the secondary antibody was detected by autoradiography using enhanced chemiluminescence (ECL Plus; GE Healthcare UK Ltd., Little Chalfont, UK). Densitometric analysis was performed to quantitate Egr-1,
TNF- $\alpha$, and actin protein using NIH imaging software. Actin protein was used as a reference for quantitation of Egr- 1 and TNF- $\alpha$ protein.

\section{Cell Experiments}

Primary VSMCs were explanted from the medial layer of each apoE-KO or D-KO mouse aorta as described previously ${ }^{21)}$. They were cultured in $75-\mathrm{cm}^{2}$ flasks for continuous growth at $37^{\circ} \mathrm{C}$ in a humidified atmosphere of $95 \%$ air and $5 \% \mathrm{CO}_{2}$ with medium changes every 3 days. The growth medium consisted of Dulbecco's modified Eagle's Medium (DMEM) (Invitrogen) supplemented with $10 \%$ fetal bovine serum (FBS; SAFC Biosciences, Wicklow, Ireland), 100 units $/ \mathrm{mL}$ penicillin, and $100 \mathrm{mg} / \mathrm{mL}$ streptomycin (Invitrogen). The VSMCs used for experiments were from the third to seventh passages. At 48 hours of incubation, the cells were harvested by trypsinization and counted in a CDA-500 Particle Analyzer (SYSMEX CORPORATION, Hyogo, Japan). At 48 hours of incubation, cytoplasmic and nuclear proteins were extracted from cultured VSMCs using the Protein and RNA Isolation System.

Peritoneal macrophages were recruited and collected from the peritoneal cavities of mice. We injected $5 \mathrm{~mL}$ of ice-cold PBS into the peritoneal cavity and harvested by lavage of the peritoneal cavity. The cells from 5 mice were incubated in DMEM supplemented with $10 \% \mathrm{FBS}$ in $75-\mathrm{cm}^{2}$ flasks at $37^{\circ} \mathrm{C}$ in a humidified atmosphere of $95 \%$ air and $5 \% \mathrm{CO}_{2}$ for 12 hours. Then, 4 hours after adding lipopolysaccharide (LPS; $25 \mathrm{ng} / \mathrm{mL}$ ), cytoplasmic and nuclear proteins were extracted from cultured macrophages using the Protein and RNA Isolation System. We examined the expression levels of Egr-1 and TNF- $\alpha$ in VSMCs and macrophages as described in the section on Western blot analysis.

\section{Statistical Analysis}

All calculated data are presented as the mean \pm SD. Statistical significance was evaluated using the unpaired Student's $t$-test for comparisons between two groups. A probability value of $p<0.05$ was considered statistically significant.

\section{Results}

\section{Body Weight and Lipid Concentrations}

At 20 weeks old, there were no significant differences in body weight (apoE-KO: $27.5 \pm 4.0 \mathrm{~g}$ vs. D-KO: $25.3 \pm 1.8 \mathrm{~g}, n=15$ in each group, Fig. 1A) and total cholesterol (apoE-KO: $554.7 \pm 160 \mathrm{mg} / \mathrm{dL}$ vs. D-KO: $576.5 \pm 161 \mathrm{mg} / \mathrm{dL}, n=15$ in each group, 
A

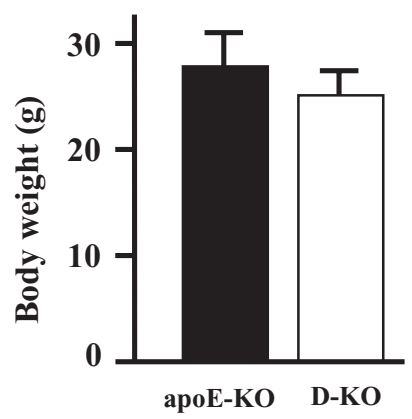

C

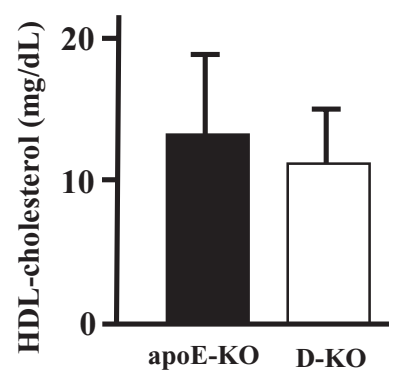

$\mathrm{B}$

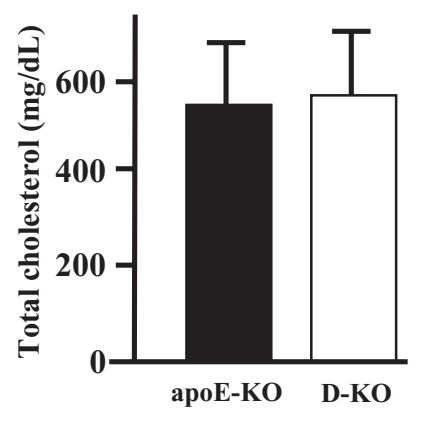

D

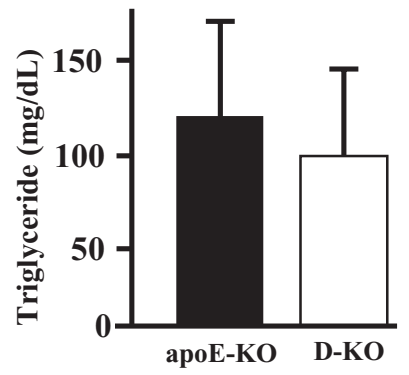

Fig. 1. Body weight and lipid concentrations at 20 weeks old in apoE-KO $\left(\mathrm{apoE}^{-/-}\right)$and $\mathrm{D}-\mathrm{KO}\left(\mathrm{CLU}^{-/-} / \mathrm{apoE}^{-/-}\right)$mice.

There were no significant differences in body weight (A), total cholesterol (B), HDL cholesterol (C), and triglyceride (D) concentrations at 20 weeks old between apoE-KO mice $(n=15$ mice, black bars) and D-KO mice ( $n=15$ mice, white bars).

Fig. 1B), HDL cholesterol (apoE-KO: 12.5 \pm 7.0 $\mathrm{mg} / \mathrm{dL}$ vs. D-KO: $10.6 \pm 4.5 \mathrm{mg} / \mathrm{dL}, n=15$ in each group, Fig. 1C), and triglyceride (apoE-KO: $119.3 \pm$ $57.3 \mathrm{mg} / \mathrm{dL}$ vs. D-KO: $100.1 \pm 47.7 \mathrm{mg} / \mathrm{dL}, n=15$ in each group, Fig. 1D) concentrations between the apoE-KO and D-KO mice. In addition, there were no differences in blood sugar levels, blood cell counts and anatomical subjects between apoE-KO and $\mathrm{D}-\mathrm{KO}$ mice.

\section{Atherosclerotic Lesions}

We analyzed atherosclerotic lesions in the aortic roots. Fig. 2A shows representative oil red O-stained cross-sections of the aortic roots of apoE-KO and $\mathrm{D}-\mathrm{KO}$ mice at 20 weeks old. The atherosclerotic area of $\mathrm{D}-\mathrm{KO}$ mice was smaller than that of apoE-KO mice. The quantification of the atherosclerotic area in the aortic root revealed that the atherosclerotic lesion of $\mathrm{D}-\mathrm{KO}$ mice was significantly smaller than that of apoE-KO mice at 20 weeks old (apoE-KO: $0.34 \pm 0.18$ $\mathrm{mm}^{2}$ vs. D-KO: $0.18 \pm 0.10 \mathrm{~mm}^{2}, p<0.05, n=15$ in each group, Fig. 2B).

A
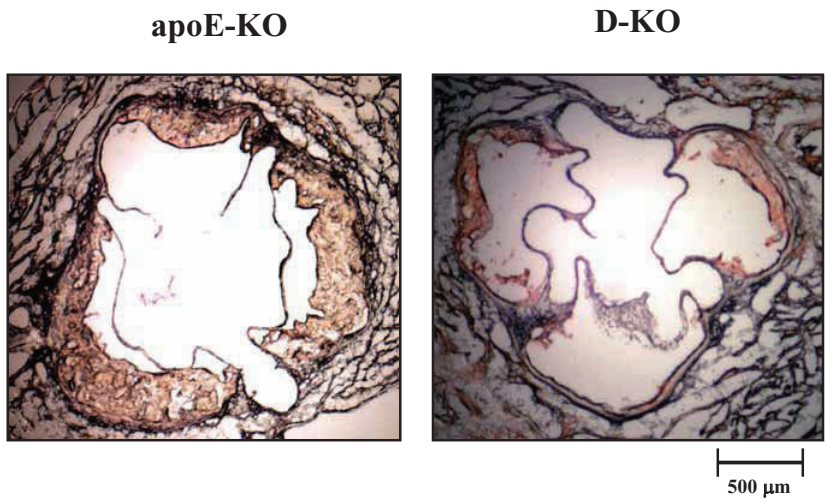

B

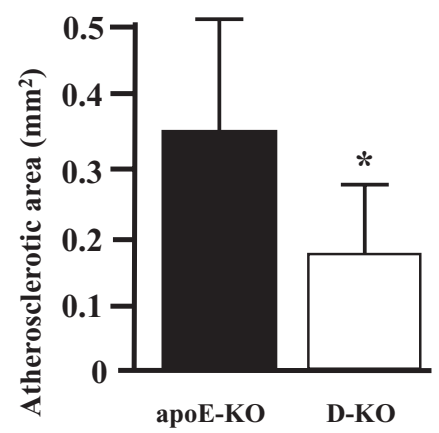

Fig. 2. Atherosclerotic lesions at 20 weeks old in apoE-KO $\left(\mathrm{apoE}^{-/-}\right)$and $\mathrm{D}-\mathrm{KO}\left(\mathrm{CLU}^{-/-} / \mathrm{apoE}^{-/-}\right)$mice.

A: Representative oil red O-stained cross-sections of the aortic roots of apoE-KO and D-KO mice at 20 weeks old. B: Quantification of the atherosclerotic volume in the aortic root. Atherosclerotic lesions in $\mathrm{D}-\mathrm{KO}$ mice $(n=15$ mice, white bars) were significantly smaller than those in apoE-KO mice $(n=15$ mice, black bars) at 20 weeks old. ${ }^{*} p<0.005$ versus apoE-KO mice.

\section{Immunohistochemistry}

We performed immunohistochemical staining using a primary antibody against Egr-1, which is an atherogenic factor and a promoter of clusterin. The expression of Egr-1 in atherosclerotic lesions of D-KO mice was lower than that of apoE-KO mice (Fig. 3A).

\section{Western Blotting}

We isolated protein from the aortas of apoE-KO or D-KO mice at 20 weeks old and used it for Western blotting. We confirmed that clusterin was expressed in atherosclerotic aorta of apoE-KO mice and was not detected in $\mathrm{D}-\mathrm{KO}$ mice. Densitometric analysis of Western blotting demonstrated that the expression levels of ERK, Egr-1, and TNF- $\alpha$ in D-KO mice were significantly lower than those in apoE-KO mice (ERK: apoE-KO $1.25 \pm 0.12$ vs. D-KO $0.14 \pm 0.07, p<0.05$; Egr-1: apoE-KO $1.07 \pm 0.10$ vs. D-KO $0.19 \pm 0.03$, $p<0.05$; TNF- $\alpha$ : apoE-KO $0.21 \pm 0.03$ vs. D-KO 
A
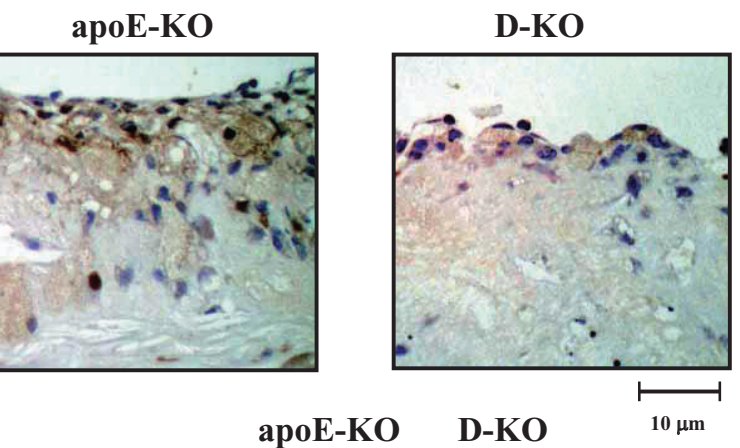

B

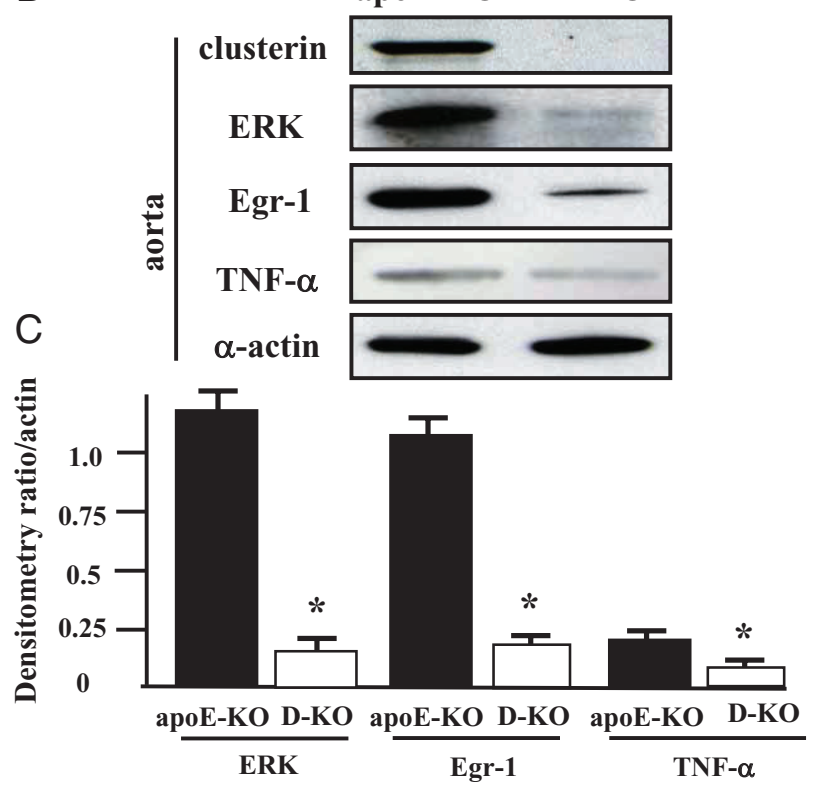

Fig. 3. Immunohistochemical staining and Western blot analysis at 20 weeks old in apoE-KO $\left(\mathrm{apoE}^{-/-}\right)$and $\mathrm{D}-\mathrm{KO}$ $\left(\mathrm{CLU}^{-1-} / \mathrm{apoE}^{-/-}\right)$mice.

A: The expression of Egr-1 in atherosclerotic lesions of D-KO mice was lower than that of apoE-KO mice. B: Representative Western blot analysis for clusterin, ERK, Egr-1, TNF- $\alpha$, and $\alpha$-actin in apoE-KO and D-KO mice. C: Densitometric analysis of Western blotting demonstrated that the expression levels of ERK, Egr-1, and TNF- $\alpha$ in the D-KO mice ( $n=3$ experiments, white bar) were significantly lower than those in apoE-KO mice $(n=3$ experiments, black bar). ${ }^{*} p<0.005$ versus apoE-KO mice.

$0.10 \pm 0.03, p<0.05, n=3$ in each group, Fig. 3B). These results suggested that clusterin deficiency reduced the expression of the Egr-1/TNF- $\alpha$ pathway.

\section{Cell Experiment}

Cultured VSMCs were explanted from the thoracic aortas obtained from apoE-KO or $\mathrm{D}-\mathrm{KO}$ mice. After 48 hours of incubation, the cell number of VSMCs obtained from D-KO mice (D-KO VSMCs) was significantly smaller than that from apoE-KO mice (apoE-KO VSMCs) (apoE-KO VSMCs: 10,165
A

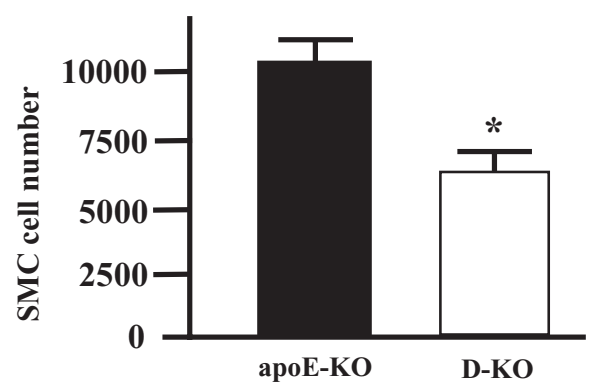

B

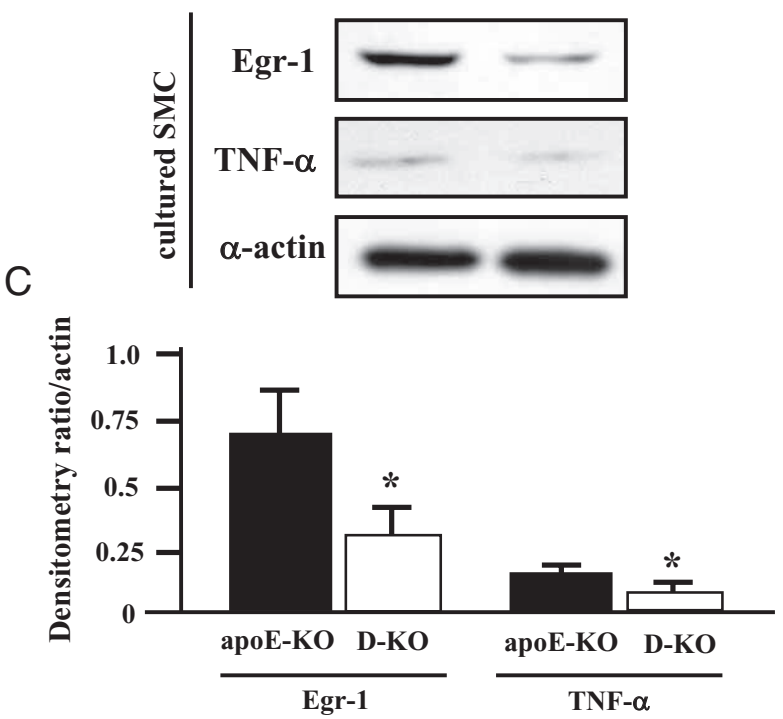

Fig.4. Cell proliferation and Western blotting for Egr-1, TNF- $\alpha$, and $\alpha$-actin of cultured VSMCs obtained from the medial layer of apoE- $\mathrm{KO}\left(\mathrm{apoE}^{-/-}\right)$or $\mathrm{D}-\mathrm{KO}$ $\left(\mathrm{CLU}^{-1-} / \mathrm{apoE}^{-1-}\right)$ mouse aortas.

A: The cell number of D-KO VSMCs ( $n=3$ experiments, white bar) was significantly smaller than that of apoE-KO VSMCs $(n=3$ experiments, black bar). B: Representative Western blot analysis for Egr-1, TNF- $\alpha$, and $\alpha$-actin of VSMCs from apoE-KO and D-KO mice. C: Densitometric analysis of Western blotting demonstrated that the expression levels of Egr- 1 and TNF- $\alpha$ of D-KO VSMCs ( $n=3$ experiments, white bar) were significantly lower than those of apoE-KO VSMCs ( $n=3$ experiments, black bar). ${ }^{*} p<0.005$ versus apoE-KO mice.

\pm 822 cells versus D-KO VSMCs: $6,825 \pm 485$ cells, $p<0.05$, Fig. 4A). Western blotting demonstrated that the expression levels of Egr-1 and TNF- $\alpha$ of D-KO VSMCs were significantly lower than those of apoE-KO VSMCs (Egr-1: apoE-KO $0.73 \pm 0.14$ vs. $\mathrm{D}-\mathrm{KO} 0.30 \pm 0.11, p<0.05$; TNF- $\alpha$ : apoE-KO 0.17 \pm 0.01 vs. $\mathrm{D}-\mathrm{KO} 0.09 \pm 0.02, \mathrm{P}<0.05, n=3$ in each group, Fig. 4B, C).

Furthermore, we analyzed the expression levels of 
A

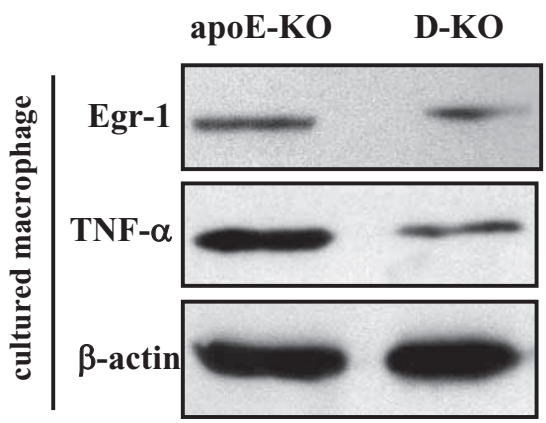

B

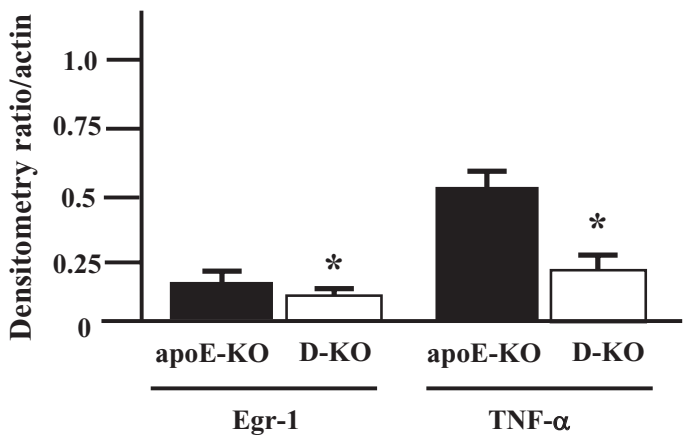

Fig. 5. Western blotting for Egr-1, TNF- $\alpha$, and $\beta$-actin of peritoneal macrophages obtained from apoE-KO $\left(\mathrm{apoE}^{-/-}\right)$or $\mathrm{D}-\mathrm{KO}\left(\mathrm{CLU}^{-/-} / \mathrm{apoE}^{-/-}\right)$mice.

A: Representative Western blot analysis for Egr-1, TNF- $\alpha$, and $\beta$-actin of peritoneal macrophages from apoE-KO mice $(n=3$ experiments, black bar) and D-KO mice $(n=3$ experiments, white bar). B. Densitometric analysis of Western blotting demonstrated that the expression levels of Egr- 1 and TNF- $\alpha$ in macrophages from $\mathrm{D}-\mathrm{KO}$ mice ( $n=3$ experiments, white bar) were significantly lower than those from apoE-KO mice $(n=3$ experiments, black bar). ${ }^{*} p<0.005$ versus apoE-KO mice.

Egr-1 and TNF- $\alpha$ in macrophages obtained from apoE-KO or D-KO mice. After stimulation by LPS, Western blotting showed that the expression levels of Egr-1 and TNF- $\alpha$ in macrophages of D-KO mice were significantly lower than those of apoE-KO mice (Egr-1: apoE-KO $0.20 \pm 0.03$ vs. D-KO $0.12 \pm 0.02$, $p<0.05$; TNF- $\alpha$ : apoE-KO $0.55 \pm 0.06$ vs. D-KO 0.23 $\pm 0.04, p<0.05, n=3$ in each group, Fig. 5).

\section{Discussion}

For the first time, we demonstrated that the atherosclerotic lesion of $\mathrm{D}-\mathrm{KO}$ mice was significantly smaller than that of apoE-KO mice. Moreover, the loss of clusterin reduced the expression of Egr-1 and TNF- $\alpha$ in the atherosclerotic lesion, and cultured VSMCs and macrophages. These results suggested that clusterin is an atherogenic factor.

Clusterin plays a dual role as a tumor suppressor and a tumor promoter. This diverse set of functions can be attributed to the existence of two alternatively spliced forms, secretory clusterin (sCLU) and nuclear clusterin (nCLU) ${ }^{22)}$. The sCLU form is cytoprotective. Recently, Kim et al. reported that sCLU inhibited the proliferation and migration of VSMCs ${ }^{23}$. In contrast, nCLU migrates to the nucleus upon cytotoxic stress to trigger cell death and interacts with the DNA doublestrand break repair antigen $\mathrm{Ku} 70$, blocking its function and causing cell death ${ }^{24)}$. In this study, Western blotting demonstrated that $\mathrm{nCLU}$, a $49-\mathrm{kDa}$ protein expressed in the atherosclerosis of apoE-KO mice, and reduced nCLU expression reduced the atherosclerotic lesions of apoE-KO mice.

Egr-1 is a promoter of clusterin and contributes to the pathogenesis of atherosclerotic lesions ${ }^{25}$. Subsequent studies comparing Egr-1 protein expression in cells derived from the human atherosclerotic lesion and media at low passage revealed greater expression in lesions ${ }^{26)}$. The lesion area in mice deficient in both Egr-1 and apoE is markedly reduced compared with that in mice lacking apoE alone ${ }^{27}$. Egr-1 is also found in inflammatory cells of vascular lesions. For example, Egr- 1 is expressed in $\mathrm{CD} 8^{+}$macrophages of aortic atherosclerotic lesions in fructose-fed low-density lipoprotein receptor-deficient mice ${ }^{28)}$. Thus, Egr-1 is found in several cell types within atherosclerotic lesions and is a factor required in atherogenesis. TNF- $\alpha$, IL-2, MCP-1, and ICAM-1 are Egr-1 target genes ${ }^{29)}$. We demonstrated that loss of clusterin reduced the activation of Egr-1/TNF- $\alpha$ in VSMCs and macrophages and reduced the atherosclerotic lesions.

Clusterin exerts a feed-forward loop including ERK activation, which leads to the up-regulation of Egr-1 and clusterin ${ }^{30}$. We confirmed that the expression of ERK and Egr-1 was down-regulated in atherosclerotic lesions of D-KO mice; therefore, we think that the down-regulation of clusterin leads to the reduction of Egr-1 via down-regulation of ERK.

We demonstrated that the proliferation of VSMC in D-KO was reduced. In addition, we showed the down-regulation of Egr-1 and TNF- $\alpha$ of D-KO VSMCs. These results suggest that clusterin deficiency down-regulates the expression of Egr-1 and TNF- $\alpha$, which leads to the suppression of VSMC proliferation.

Macrophages play an important role in atherosclerosis. We demonstrated that the expression of Egr-1 and TNF- $\alpha$ was down-regulated in macrophages obtained from $\mathrm{D}-\mathrm{KO}$ mice; therefore, the reduction of Egr- 1 and TNF- $\alpha$ expression in macrophages may also lead to the reduction of atherosclerosis in $\mathrm{D}-\mathrm{KO}$ mice. 
In addition, clusterin is reported to inhibit the migration and adhesion of human umbilical vein endothelial cells ${ }^{31)}$.

Clusterin is identical to apolipoprorein J; however, there were no significant differences in total cholesterol, HDL cholesterol, and triglyceride levels between apoE-KO and D-KO. Therefore, we think that clusterin deficiency did not reduce atherosclerosis via lipoprotein metabolism in this study.

Intravenous infusion of the antisense oligonucleotide of clusterin, which is called OGX-011, has been approved for clinical phase III trials in prostate cancer. OGX-011 may be used for the prevention or regression of atherosclerosis.

In conclusion, loss of clusterin strongly suppressed apoE-KO induced atherosclerotic lesions at a step prior to the expression of Egr- 1 and TNF- $\alpha$, suggesting that clusterin is a candidate for an antiatherogenic target.

\section{Acknowledgments}

This study was supported in part by a Grant-inaid for Scientific Research from the Japan Society for the Promotion of Science (No. 16590701).

\section{Disclosures}

None.

\section{References}

1) Libby P: Inflammation in atherosclerosis. Nature, 2002; 420: 868-874

2) Corrado E, Rizzo M, Coppola G, Fattouch K, Novo G, Marturana I, Ferrara F, Novo S: An update on the role of markers of inflammation in atherosclerosis. J Atheroscler Thromb, 2010; 17: 1-11

3) Ross R: Atherosclerosis: an inflammatory disease. N Engl J Med, 1999; 340: 115-126

4) Glass CK, Witztum JL: Atherosclerosis: the road ahead. Cell, 2001; 104: 503-516

5) Aronow BJ, Lund SD, Brown TL, Harmony JA, Witte DP: Apolipoprotein J expression at fluid-tissue interfaces: potential role in barrier cytoprotection. Proc Natl Acad Sci USA, 1993; 90: 725-729

6) Jones SE, Jomary C: Clusterin. Int J Biochem Cell Biol, 2002; 34: 427-431

7) Shannan B, Seifert M, Leskov K, Willis J, Boothman D, Tilgen W, Reichrath J: Challenge and promise: roles for clusterin in pathogenesis, progression, and therapy of cancer. Cell Death Differ, 2006; 13: 12-19

8) Trougakos IP, Poulakou M, Stathatos M, Chalikia A, Melidonis A, Gonos ES: Serum levels of the senescence biomarker clusterin/apolipoprotein J increase significantly in diabetes type II and during development of coronary heart disease or at myocardial infarction. Exp Gerontol, 2002; 37: 1175-1187

9) Swertfeger DK, Witte DP, Stuart WD, Rockman HA, Harmony JA: Apolipoprotein J/clusterin induction in myocarditis: A localized response gene to myocardial injury. Am J Pathol, 1996; 148: 1971-1983

10) McGeer PL, Kawamata T, Walker DG: Distribution of clusterin in Alzheimer brain tissue. Brain Res, 1992; 579: 337-341

11) Klock G, Storch S, Rickert J, Gutacker C, Koch-Brandt C: Differential regulation of the clusterin gene by $\mathrm{Ha}$-ras and c-myc oncogenes and during apoptosis. J Cell Physiol, 1998; 177: 593-605

12) Viard I, Wehrli P, Jornot L, Bullani R, Vechietti JL, Schifferli JA, Tschopp J, French LE: Clusterin gene expression mediates resistance to apoptotic cell death induced by heat shock and oxidative stress. J Invest Dermatol, 1999; 112: 290-296

13) Miyata M, Biro S, Kaieda H, Eto H, Orihara K, Kihara T, Obata H, Matsushita N, Matsuyama T, Tei C: Apolipoprotein $\mathrm{J} /$ clusterin is induced in vascular smooth muscle cells after vascular injury. Circulation: 2001; 104: $1407-$ 1412

14) Millis AJ, Luciani $M$, McCue HM, Rosenberg ME, Moulson CL: Clusterin regulates vascular smooth muscle cell nodule formation and migration. J Cell Physiol, 2001; 186: 210-219

15) Orlandi A, Pucci S, Ciucci A, Pichiorri F, Ferlosio A, and Spagnoli LG: Modulation of clusterin isoforms is associated with all-trans retinoic acid-induced proliferative arrest and apoptosis of intimal smooth muscle cells. Arterioscler Thromb Vasc Biol, 2005; 25: 348-353

16) Shirasawa T, Miyata M, Eto H, Hamada N, Akasaki $Y$, Miyauchi T, Furusho Y, Orihara K, Hamasaki S, Aronow BJ, Smith JD, Tei C: Deficiency of clusterin inhibits neointimal hyperplasia after vascular injury. J Atheroscler Thromb, 2009; 16: 772-781

17) McLaughlin L, Zhu G, Mistry M, Ley-Ebert C, Stuart WD, Florio CJ, Groen PA, Witt SA, Kimball TR, Witte DP, Harmony JA, Aronow BJ: Apolipoprotein J/clusterin limits the severity of murine autoimmune myocarditis. J Clin Invest. 2000; 106: 1105-1113

18) Smith JD, Trogan E, Ginsberg M, Grigaux C, Tian J, Miyata M: Decreased atherosclerosis in mice deficient in both macrophage colony-stimulating factor (op) and apolipoprotein E. Proc Natl Acad Sci USA, 1995; 92: 82648268

19) Akasaki $Y$, Miyata M, Eto $H$, Shirasawa T, Hamada $N$, Ikeda Y, Biro S, Otsuji Y, Tei C: Repeated thermal therapy up-regulates endothelial nitric oxide synthase and augments angiogenesis in a mouse model of hindlimb ischemia. Circ J, 2006; 70: 463-470

20) Hamada N, Miyata M, Eto H, Shirasawa T, Akasaki $Y$, Nagaki A, Tei C: Tacrolimus-eluting stent inhibits neointimal hyperplasia via calcineurin/NFAT signaling in porcine coronary artery model. Atherosclerosis, 2010; 208: $97-103$

21) Obata $H$, Biro $S$, Arima $N$, Kaieda $H$, Kihara $T$, Eto $H$, Miyata M, Tanaka H: NF-kappa B is induced in the 
nuclei of cultured rat aortic smooth muscle cells by stimulation of various growth factors. Biochem Biophys Res Commun, 1996; 224: 27-32

22) Trougakos IP, Djeu JY, Gonos ES, Boothman DA: Advances and challenges in basic and translational research on clusterin. Cancer Res, 2009; 69: 403-406

23) Kim HJ, Yoo EK, Kim JY, Choi YK, Lee HJ, Kim JK, Jeoung NH, Lee KU, Park IS, Min BH, Park KG, Lee $\mathrm{CH}$, Aronow BJ, Sata M, Lee IK: Protective role of clusterin/apolipoprotein J against neointimal hyperplasia via antiproliferative effect on vascular smooth muscle cells and cytoprotective effect on endothelial cells. Arterioscler Thromb Vasc Biol, 2009; 29: 1558-1564

24) Leskov KS, Klokov DY, Li J, Kinsella TJ, and Boothman DA: Synthesis and functional analyses of nuclear clusterin, a cell death protein. J Biol Chem, 2003; 278: 11590-11600

25) Khachigian LM: Early growth response-1 in cardiovascular pathobiology. Circ Res, 2006; 98: 186-191

26) Du B, Fu C, Kent KC, Bush H, Schulick AH, Kreiger K, Collins T, McCaffrey TA: Elevated Egr-1 in human atherosclerotic cells transcriptionally represses the transforming growth factor-b type II receptor. J Biol Chem, 2000;
275: 39039-39047

27) Harja E, Bucciarelli LG, Lu Y, Stern DM, Zou YS, Schmidt AM, Yan SF: Early growth response-1 promotes atherogenesis: mice deficient in early growth response-1 and apolipoprotein $\mathrm{E}$ display decreased atherosclerosis and vascular inflammation. Circ Res, 2004; 94: 333-339

28) Goetze S, Kintscher U, Kaneshiro K, Meehan WP, Collins A, Fleck E, Hsueh WA, Law RE: TNFalpha induces expression of transcription factors c-fos, Egr-1, and Ets-1 in vascular lesions through extracellular signal-regulated kinases 1/2. Atherosclerosis, 2001; 159: 93-101

29) Blaschke F, Bruemmer D, Law RE: Egr-1 is a major vascular pathogenic transcription factor in atherosclerosis and restenosis. Rev Endocr Metab Disord, 2004; 5: 249254

30) Zoubeidi A, Chi K, Gleave M: Targeting the cytoprotective chaperone, clusterin, for treatment of advanced cancer. Clin Cancer Res, 2010; 16: 1088-1093

31) Sivamurthy N, Stone DH, Logerfo FW, Quist WC: Apolipoprotein $\mathrm{J}$ inhibits the migration, adhesion, and proliferation of vascular smooth muscle cells. J Vasc Surg, 2001; 34: 716-723 